\title{
Diferenças de Gêneros nos Grupos de Brincadeira na Rua: A Hipótese de Aproximação Unilateral
}

\author{
Gender Differences in the Groups of Street Play: \\ The Hypothesis of Unilateral Approach
}

\author{
Lúcia Isabel da Conceição Silvaa, Fernando Augusto Ramos Pontesa*, Sarah Danielle Baia da \\ Silva $^{a}$, Celina Maria Colino Magalhães ${ }^{\mathrm{a}}, \&$ Ilka Dias Bichara ${ }^{\mathrm{b}}$ \\ ${ }^{a}$ Universidade Federal do Pará, ${ }^{b}$ Universidade Federal da Bahia
}

\begin{abstract}
Resumo
Este estudo investigou aspectos da diferenciação sexual em brincadeiras de crianças/adolescentes na rua Participaram 668 pessoas entre 1 e 18 anos (245 meninas - 423 meninos), moradores/visitantes de três ruas num bairro da periferia de Belém, durante 1 ano. Foram observadas diferenças de gênero quanto à participação na rua e à variedade de subcultura lúdica. Observou-se predominância dos meninos na rua, segregação e tipificação sexual nas brincadeiras e maior penetração das meninas na subcultura masculina. Os dados sobre composição dos grupos, segregação, tipificação e preferência por brincadeiras levam à hipótese de aproximação unilateral entre os grupos de gênero.

Palauras-chave: Brincadeiras; crianças; gênero; diferenças de gênero.
\end{abstract}

\begin{abstract}
This study examined aspects of sex differentiation among children and adolescents engaged in play activities in the street. The participants included 668 individuals between the ages of one and 18 years (245 girls and 423 boys), residing near three streets in a peri-urban area of Belém, during a one-year period. Scan sampling was utilized and the following variables were recorded: the identity and number of participants, group composition, type of play activity, age and play locale. There were gender differences related to the frequency of participation and types of activity. Although males were more numerous than females in the street, and play activities were largely sex-typified and segregated, females tended to participate in masculine dominant activities. The data on group composition, segregation, typology, game and toy preference lead us to infer the presence of gender-related unilateral approximation.

Keywords: Play; children; gender; sex differences.
\end{abstract}

As diferenças relacionadas aos gêneros estão presentes em praticamente todas as sociedades, nas quais é sempre possível perceber exemplos de como os sexos/gêneros diferem nas características físicas, nas formas de comportarse, nos aspectos relacionados a poder e a status dentro dos grupos, nos papéis e ideologia de papéis, na divisão de tarefas e expectativas de comportamento. Diversos estudos parecem relacionar essas diferenças e as práticas de socialização em cada sociedade ou cultura (Afonso, 1995; Archer, 1992; Harris, 1999; Maccoby, 1988; Segall, Dasen, Berry, \& Poortinga 1990).

Falar de sexo, como característica fisiológica e anatômica significa sempre falar de dois grupos de indivíduos determinados pela Biologia: macho ou fêmea. Entretanto, a estes dois subgrupos são "coladas" progressivamente características, comportamentos e significados culturais a

Apoio: $\mathrm{CNPq}$

* Endereço: UFPA, CFCH, Psicologia Experimental. Rua Augusto Correa s/n, Lab. de Psicologia, Guamá, 66075 110, Belém, PA. Fone: 2111453,Fax: 2111662.farp@cpgp.ufpa.br respeito do que é ser feminino ou ser masculino, o que se dedenomina gênero.

Pode-se dizer que a base das diferenciações de gênero é biológica, mas as construções que se processam e a forma como se processam são simbólicas, são sociais. Isso justifica, portanto, a necessidade de situar a discussão dentro de uma perspectiva mais aberta e integrada, permitindo uma visão mais ampliada do fenômeno da diferenciação de gênero e da autocategorização, percebendo-se como fatores biológicos e culturais interagem.

\section{Os Companheiros de Grupo Como Elementos Socializadores}

Algumas mudanças em termos de papéis e ideologia de gênero podem ser testemunhadas no contexto atual. Com os homens se dedicando às tarefas de casa e cuidado das crianças e as mulheres ocupando, cada vez mais, cargos e funções antes “reservados" aos homens. Entretanto, as pesquisas na área ainda revelam o desenvolvimento e manutenção pelas crianças de características e posturas sexualmente estereotipadas (Alexander \& Hines 1994; Beraldo 1993; Harris 1999; Johnson, Christie, \& Yawkey, 
1999; Maccoby 1988; Martin \& Fabes 2001; Weinraub et al., 1984; entre outros). O que estes estudos parecem indicar é que meninas e meninos nascem diferentes e tornam-se ainda mais diferentes no decorrer dos anos pré-escolares e escolares. Se a cultura adulta está mais igualitária, por que a segregação sexual continua sendo uma marca forte da infância?

A cultura adulta no decorrer dos tempos se modificou (ou se modifica) mais rapidamente que a das crianças. "Os adultos reviram suas idéias, mas as crianças não” (Harris, 1999 p.278). A autora se utiliza dessa evidência para afirmar que o maior peso na formação destes e de outros valores são dos pares e de seus grupos e não dos pais.

Idéia semelhante é defendida por Carvalho e Pedrosa (2002) ao referirem-se ao grupo de crianças brincando como microssociedade, tendo a criança como agente de criação, partilha e transmissão de cultura. O grupo de brincadeiras pode ser pensado então como um contexto de desenvolvimento, um micro meio ambiente, um espaço de confronto e negociação, mediador do processo de abstração das regras sociais e cognitivas, incluindo, aí, as noções de diferenciação e papéis de gênero. A segregação e a tipificação sexual não são, portanto, um reflexo de preferências individuais, mas um fenômeno de grupo (Maccoby, 1988).

As crianças se socializam umas às outras e esta socialização, entendida como aprendizagem ou incorporação de valores, regras e comportamentos adequados dentro da sociedade, tem como base um processo de construção de identidade, ou de autocategorização (Camaione, 1980; Harris, 1999). Uma vez que as formas de comportar-se não são homogêneas, mas categorizadas, e, na maioria das vezes, de forma oposta (homens e mulheres; adultos e crianças, meninos e meninas etc.), as crianças precisam então descobrir ou decidir quem são, onde se encaixam, a que grupo pertencem, para a partir daí trabalhar esta inserção. A criança se compara aos pares, e assim as meninas se tornam mais parecidas com as outras meninas e os meninos com os outros meninos.

Em linha semelhante de argumentação, diversos outros estudos também têm enfatizado a importância e o significado da interação entre crianças no seu processo de desenvolvimento (Beal, 1994; Camaione, 1980; Carvalho, 1989, 1992; Eibl-Eibesfeldt, 1989; Lordelo, 1995; Martin \& Fabes, 2001; Pedrosa \& Carvalho, 1995; Pontes, 2000).

Se pensarmos na importância dos pares na socialização das crianças e em um espaço de grandes e significativas possibilidades de interação, certamente chegaremos ao processo de interação em situação de brincadeira na rua como um contexto disponibilizador de informações sobre o desenvolvimento das noções de diferenciação na criança.

Nos grupos de rua, as crianças se organizam a partir de seus critérios, sem as restrições impostas pelos adultos, sendo a rua, por isso, um espaço mais propício ao estabelecimento de relações mais simétricas, menos hierárquicas, caracterizadas por reciprocidade e harmonia (Eibl-Eibesfeldt, 1989). Talvez seja ainda prematuro falar da existência ou não desta simetria de relações. Por ora vale dizer que as referências de estudo na área fornecem bases suficientes para pensar o grupo de rua como "um fenômeno paradigmático" das formas próprias de organização social da criança (Pontes, 2000). Considera-se que dentro do grupo a criança aprende tanto as regras da brincadeira quanto as de comportamentos, os papéis, os limites e as sanções para os comportamentos não apropriados.

\section{Os Gêneros nas Brincadeiras Infantis}

Se a socialização ocorre não a partir da categoria geral de crianças, mas por categorias específicas de meninos ou meninas, quais diferenciações em termos de gênero são possíveis encontrar neste contexto?

O gênero é a categoria que responde pelas informações necessárias para a compreensão sobre padrões e estilos, formas de inserção na brincadeira e preferências, sendo determinante das expectativas de comportamentos num grupo de brincadeiras e o principal critério para a formação de grupos de brincadeiras já a partir dos três anos de idade (Beal, 1994; Johnson et al., 1999; Maccoby, 1990).

Estudos apontam diferenças de estilos e preferências de brincadeiras, atitudes, compor tamentos, percepções, escolha de parceiros, tamanho de grupos, construção de estereótipos e justificativa para exclusão com base nestes estereótipos (Archer, 1992; Beraldo, 1993; Maccoby, 1988, 1990, 1991). É praticamente consensual entre os pesquisadores a percepção de que as preferências para parceiros/as de brincadeira são para crianças do mesmo sexo e que esta começa a ser demonstrada bem cedo, se mantendo (com tendência a aumentar) durante a infância.

Os padrões de interação também são distintos. Os meninos brincam em grupos maiores e são mais preocupados com status e reputação dentro dos grupos, são mais rígidos com seus papéis de gênero e mais preocupados em rejeitar a feminilidade, enquanto as meninas são mais intimistas nas interações, mais cooperativas, fazem mais trocas de confidências e são mais flexíveis. As diferenças também se apresentam em relação ao uso do espaço com os meninos ocupando espaços maiores e públicos (Archer 1992; Beal 1994; Maccoby 1988, 1990). Mesmo em grupos mistos o comportamento de cada sexo é bastante diferente.

Um aspecto adicional sobre a questão da diferenciação sexual é levantado por Martin e Fabes (2001), que discutem as conseqüências das preferências por parceiros de brincadeira para o desenvolvimento e analisam essas conseqüências a partir da consideração das qualidades das brincadeiras em meninos e meninas.

Para os autores, grupos segregados representam fortes elementos socializadores, influenciando tanto interações tipificadas e estilos de brincar quanto o próprio fenômeno da segregação, uma vez que teriam um papel reforçador ou monitorador de comportamentos. São examinados dois tipos de padrão de diferenciação sexual: o primeiro denominado polarização dual, no qual os comportamentos dos dois grupos de sexo se distanciariam a partir de um ponto inicial em direções opostas, e o padrão de polarização 
singular, de acordo com o qual o comportamento de apenas um dos sexos mudaria através do tempo, enquanto o outro permaneceria relativamente estável. Ambos padrões têm como conseqüência o aumento da diferenciação entre os sexos, embora em proporções diferentes.

A despeito da importância da diferenciação de gênero na interação social de crianças, o número de pesquisas que detalhem ou descrevam estas relações no ambiente da rua ainda é limitado. Esta pode ser talvez uma questão decorrente da pouca evidência do fenômeno nas sociedades industrializadas.

De qualquer forma, em algumas cidades a brincadeira e a estreita convivência das crianças/adolescentes na rua são uma realidade o que torna esse contexto um importante disponibilizador de evidências descritivas sobre a diferenciação de gênero, sua natureza e suas inter-relações. É um pouco deste cenário que o presente trabalho pretende explorar aqui com dados e reflexões referentes aos grupos de brincadeiras encontrados em um bairro periférico da cidade de Belém, região norte do Brasil.

\section{Método}

\section{Participantes}

Seiscentos e sessenta e oito crianças e adolescentes, de 1 a 18 anos (423 meninos e 245 meninas) moradores (ou visitantes) em três ruas de um bairro de periferia da cidade de Belém - Pará.

\section{Local}

A pesquisa foi realizada em três passagens interligadas, no bairro da Terra Firme, periferia da cidade de Belém: Passagem Samaumeira (a maior delas), Passagem Park Amazônia (que é uma bifurcação da primeira) e Passagem Angelim, uma passagem menor, que liga as outras duas. As ruas não possuíam serviço de esgoto nem pavimentação, sendo habitadas por população com renda média entre um e dois salários mínimos, e baixa escolaridade $(m=3,87$ anos de estudo / pessoa).

\section{Procedimentos}

\section{- Etapa 1: Caracterização do Local}

Foi feita a descrição dos aspectos demográficos, econômicos e educacionais do local da pesquisa a partir de um cadastro dos moradores da área (Passagem Samaumeira: casa 1 até casa 160; Passagem Park Amazônia: casa 1 até casa 37 e Passagem Angelim: casas 1A e 1B), com informações sobre total de moradores na casa, naturalidade, idade, sexo, nível de parentesco, nível de instrução, tempo de residência no local, renda familiar, tipo de ocupação e dimensões da residência.

- Etapa 2: Descrição das Atividades de Brincadeira na Rua

Os dados foram coletados de janeiro a dezembro de 2001 , nos períodos matutino (10 às $12 \mathrm{~h}$ ), vespertino (16 às $18 \mathrm{~h}$ ) e noturno (19 às $21 \mathrm{~h}$ ). Para a descrição das atividades infantis foi utilizada a técnica de varredura (Altmann, 1974).
As varreduras da configuração dos participantes na rua foram feitas a cada trinta minutos e tiveram como referência a localização das residências. Numa folha de registro foram coletados hora, local, nome da brincadeira, modalidade da brincadeira, nome dos sujeitos e função destes no grupo de forma a descrever o fluxo de atividades de brincadeira, a presença dos participantes, a composição dos grupos em termos de gênero e as preferências por brincadeiras.

\section{Resultados e Discussões}

\section{Diferenças na Participação Quanto ao Sexo}

Foram colhidos 17379 registros de grupos de crianças/ adolescentes brincando na rua, sendo que destes 13680 são registros de meninos e 3699 são de meninas. Este é o primeiro dado relevante sobre uma ocupação sexualmente diferenciada da rua como um espaço de brincadeira.

No que se refere às diferenças na participação absoluta na rua, foram obtidos registros de 100\% dos meninos moradores de até 14 anos brincando, contra apenas $91 \%$ das meninas. Embora pequena (9\%), essa diferença pode ser indicativa de uma maior pressão adulta sobre as meninas, já que algumas não têm permissão dos pais (ou das mães) para brincar na rua.

Mesmo tendo em mente que a população feminina da área (até 18 anos) é menor, a variação quanto ao uso da rua para brincar e quanto à freqüência com que o fazem é nitidamente maior entre os dois grupos de sexo (moradores: 59,98\% masculino - 43,02\% feminino; brincantes na rua: $63,32 \%$ masculino - 36,67\% feminino; freqüência na rua: $78,71 \%$ masculino $-21,28 \%$ feminino).

Um olhar mais individualizado sobre a freqüência de registros também revela diferenças que corroboram a maior participação masculina na rua: os meninos têm maior média de registros $(32,34)$ que as meninas $(15,09)$ e a maior freqüência individual (maior registro dos meninos $=216$; maior registro das meninas=136); os 21 maiores registros individuais também são de meninos. Os meninos têm também maior número de registros nas diversas faixas de idade (ver Figura 1).

Entre os meninos, a maior ocorrência de brincadeiras situa-se na faixa dos 7 aos 12 anos, enquanto que entre as meninas a maior ocorrência está na faixa dos quatro aos nove anos. Essa diferença pode sugerir uma relação entre o aumento da idade e o aumento da responsabilidade com as tarefas domésticas e também das pressões por padrões de comportamentos mais "recatados", condizentes com as expectativas dos papéis femininos adultos. Percebe-se, ainda, que na faixa dos quatro aos seis anos meninos e meninas parecem dispor do mesmo tempo livre para a rua, período em que as quantidades de registros praticamente se equiparam. A faixa dos 13 aos 15 anos indica uma tendência ao "recolhimento" das meninas, enquanto os meninos ainda estão "senhores" da rua e do seu tempo.

A participação das meninas, entretanto, é significativa. Elas estão bastante presentes em grupos de brincadeiras, tanto brincando quanto observando a atividade em curso e 
Silva, Pontes, Silva, Magalhães \& Bichara (2006). Diferenças de Gêneros nos Grupos de Brincadeira na Rua: A Hipótese de Aproximação Unilateral.

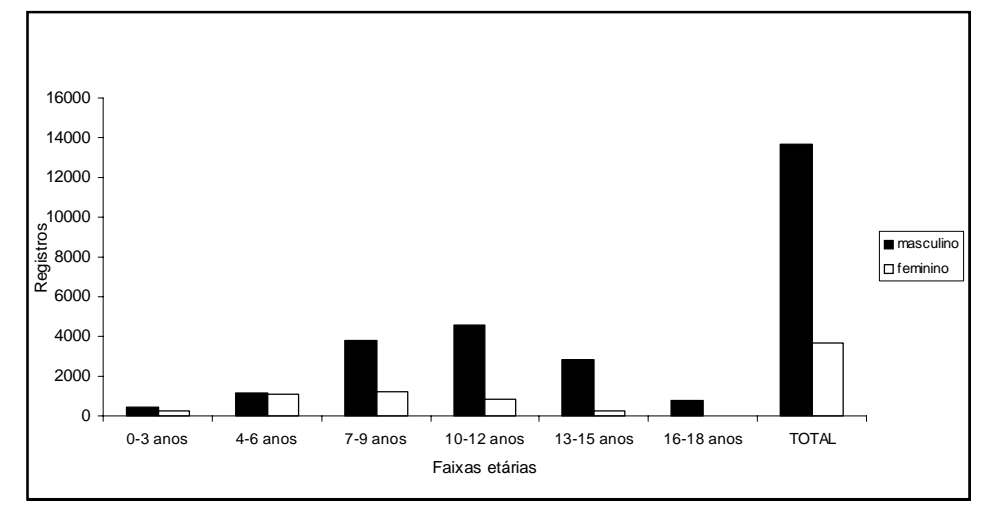

Figura 1. Frequência de registros de crianças por idade e sexo.

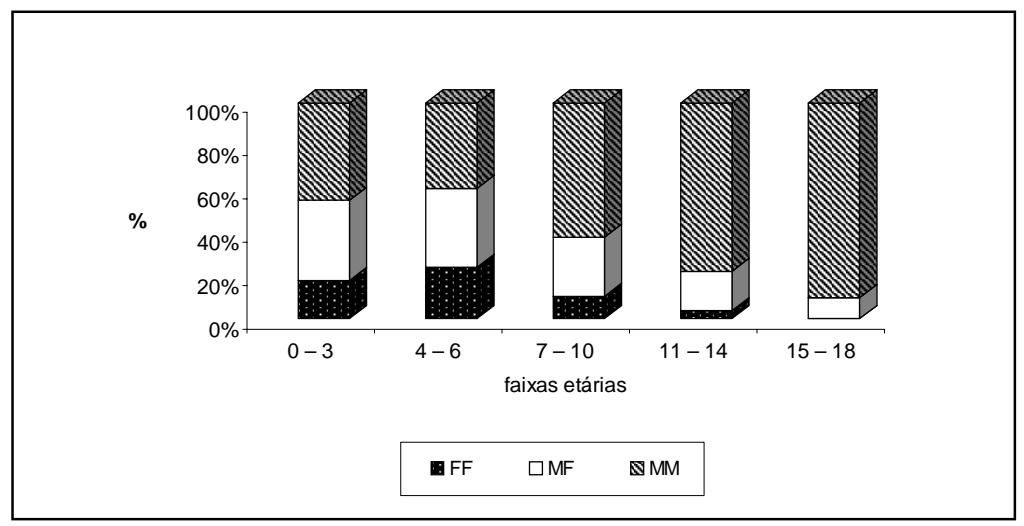

Figura 2. Relação entre as faixas etárias e composição dos grupos.

essa participação expressa idiossincrasias significativas. Foram tomados 3699 registros de participação feminina na rua, sendo que destes $82,40 \%$ estão na categoria de brincantes e $17,14 \%$ na de observadoras. Também praticamente metade das participações das meninas ocorrem em grupos mistos $(50,1 \%)$, o que pode tanto estar relacionado com a menor disponibilidade de parceiros de mesmo sexo, já que, há menos meninas que meninos brincando na rua, quanto com a preferência por estilos, brincadeiras e companhia.

Os grupos masculinos (Mm) são os preferidos pelas meninas para a atividade de observação das brincadeiras, com 49,44\% do total de observações. A grande presença das meninas em grupos mistos ou de meninos, além de sugerir atração pelos pares de outro sexo, seus estilos e brincadeiras, torna o grupo masculino um importante contexto de referência e aprendizagem para elas; o inverso acontece com os meninos que preferem brincar com meninos e observar suas brincadeiras, com $84,74 \%$ do total de observações. Apenas 3,14\% dos registros de observações dos meninos são em grupos exclusivos de meninas.

A segregação, uma característica comum nos grupos de brincadeira, é expressivamente maior entre os meninos: 82,23\% de registros em grupos homogêneos masculinos contra $41,36 \%$ de registros em grupos homogêneos femininos. No caso das meninas, esses dados contrariam estudos anteriores (Martin \& Fabes, 2001; Maccoby, 1988) segundo os quais a tendência das crianças é de participação em grupos de mesmo sexo. O percentual de integração com o outro sexo (participação em grupos mistos + grupos de outro sexo) entre as meninas é de $59 \%$, já os meninos parecem se aproximar mais da tendência à aproximação de parceiros de mesmo sexo apresentando um percentual de interação com o outro sexo de apenas $18 \%$.

Os dados também indicam uma relação entre a segregação por grupos de sexo nas brincadeiras e a idade das crianças (ver Figura 2).

Essa relação se dá em sentido inverso nos três tipos de composição de grupos. Entre as meninas, as brincadeiras em grupos de mesmo sexo, além de serem pouco freqüentes, tendem a diminuir com o aumento da idade. Entre os meninos, inversamente, a segregação aumenta expressivamente com a idade, aspecto possivelmente relacionado à diminuição do número de meninas de faixas etárias mais elevadas na rua.

A comparação dos dados demonstra, entretanto, que, acima e além das diferenças no número de moradores e na freqüência de participação na rua, as meninas tendem a segregar menos, o que significa dizer que, estas mesmo brincando menos na rua, quando o fazem, fazem mais em grupos mistos que em grupos de mesmo sexo, fato que pode estar relacionado à menor disponibilidade de parceiros de mesmo sexo. 
Sugere-se que, a brincadeira em grupos segregados por sexo significa a possibilidade de contextos de aprendizagem e reforçamento de compor tamentos tipificados, a limitação a práticas e comportamentos “apropriados" para cada sexo e, com isso, a construção/manutenção de estereótipos de papéis sexuais. Uma vez que a segregação entre os meninos é maior, então maior seria também essa possibilidade de tipificação entre eles, o que pode estar relacionado à maior rigidez de estereótipos entre os meninos.

Para identificar melhor essa tendência à segregação foi feita a análise de dados individuais. Foram tomados os 10 indivíduos de cada sexo com maior número de registro e para esses participantes foi calculado o percentual de segregação sexual sobre o total geral de registros de cada participante em relação ao total de registros em grupos de mesmo sexo (ver Tabela 1).

Embora não haja nenhum menino que brinque exclusivamente com o mesmo sexo, o percentual de participação em grupos mistos é muito baixo, indicando forte segregação masculina. Nestes os percentuais de segregação situam-se entre 72,05\% e 95,65\%, chegando a quase $100 \%$ em alguns. Novamente, se os meninos gastam mais tempo em grupos de mesmo sexo, isto significa maior exposição a experiências de comportamentos tipificados e maior possibilidade de estereotipização entre os meninos. Entre as meninas o percentual de segregação é nitidamente mais baixo, variando entre $16,41 \%$ e $55 \%$.

Entre as meninas há também maior variação entre o maior e o menor percentual de segregação: $38,59 \%$ contra 23,6\% de variação entre os meninos o que pode significar também maior variação de compor tamento entre elas. É como se as meninas "circulassem mais" por entre os grupos e as brincadeiras. Também não se verifica nenhuma menina que brinque exclusivamente com o mesmo sexo e em duas delas (Lili e Mari), a aproximação com os meninos é maior, sendo que a Lili é a que mostra o menor percentual de segregação $(16,41 \%)$.

Tabela 1

Percentual de Segregação
Parece ser possível afirmar que as meninas segregam menos. Mesmo o mais alto percentual de segregação das meninas fica bem abaixo do menor percentual dos meninos (55\% / 72,05\%).

As meninas gastam menor tempo em atividades com o mesmo sexo, o que, em tese, pode significar menor possibilidade de exposição a experiências unicamente tipificadas para o sexo feminino, logo, menor rigidez de papéis e estereótipos de adequação/inadequação de comportamentos. Por outro lado, há maior contato com a rigidez de papéis e estereótipos masculinos.

\section{Gênero e Preferência por Brincadeiras}

Foram encontradas 271 brincadeiras, havendo algumas pouco freqüentes (com 1 ou 2 registros) e outras campeãs de preferência como a peteca (2953 registros), o papagaio (2779 registros) e o futebol (2313 registros).

Em relação à idade, foi observado que a maioria das brincadeiras é etariamente partilhada, sendo brincadas por diferentes faixas de idade. Esta tendência se repete em relação ao perfil de gênero. O perfil tipicamente homogêneo de sexo não é freqüente e entre as 12 brincadeiras preferidas cinco são coincidentes: peteca (bola de gude), papagaio (incluindo variações: pipa, cangula, curica e rabiola), baralho, pira (pega-pega ou pegador) e tacobol, sendo que, destas, a peteca parece ser a mais “democrática”, tendo alta preferência nos dois grupos de gênero ( $2^{\circ}$ lugar).

Os dados revelaram uma ligeira tendência à estereotipização das brincadeiras que foram tipificadas e caracterizadas em função da participação de gênero por meio do Índice de Preferência Sexual por brincadeira (IPS). Esta caracterização foi feita com base no número de brincantes. O IPS é obtido a partir da seguinte fórmula:

$$
\text { IPS } x=\underline{\text { TPM }- \text { TPF }}
$$

Onde:

$\mathrm{X}=$ brincadeira;

TPM = Total de participação masculina; $\mathrm{TPF}=$ Total de participação feminina.

\begin{tabular}{|c|c|c|c|c|c|c|c|c|c|c|c|}
\hline \multirow{3}{*}{ Particip. } & \multicolumn{4}{|c|}{ Meninos } & \multirow{3}{*}{$\% *$} & \multirow{3}{*}{ Particip. } & \multicolumn{4}{|c|}{ Meninas } & \multirow{3}{*}{$\% *$} \\
\hline & \multirow[t]{2}{*}{ Idade } & \multicolumn{3}{|c|}{ Participação por grupos } & & & Idade & Par & ção p & upos & \\
\hline & & $\mathrm{Ff}$ & Mf & $\mathrm{Mm}$ & & & & $\mathrm{Ff}$ & Mf & $\mathrm{Mm}$ & \\
\hline Diel & 9 & - & 40 & 176 & 81,48 & Assu & 12 & 44 & 84 & 08 & 32,35 \\
\hline Elit & 9 & - & 28 & 181 & 86,60 & Lili & 12 & 22 & 87 & 25 & 16,41 \\
\hline Alex & 8 & $\mathrm{O} 2$ & 52 & 152 & 73,78 & Jani & 8 & 57 & 57 & 03 & 48,71 \\
\hline Thia & 12 & - & 18 & 187 & 91,21 & Hele & 6 & 53 & 54 & $\mathrm{O} 2$ & 48,62 \\
\hline Jode & 12 & 01 & 24 & 158 & 86,34 & Mari & 9 & 30 & 67 & 11 & 27,77 \\
\hline Carl & 13 & - & 20 & 145 & 87,88 & Elza & 10 & 48 & 50 & 07 & 45,71 \\
\hline Will & 11 & - & 08 & 155 & 95,09 & Jéssi & 4 & 55 & 40 & 05 & 55,0 \\
\hline Fran & 13 & - & 25 & 136 & 84,47 & Tais & 7 & 44 & 33 & 11 & 50,0 \\
\hline Rena & 9 & - & 07 & 154 & 95,65 & Hecri & 6 & 37 & 48 & $\mathrm{O} 2$ & 42,52 \\
\hline Valt & 7 & 03 & 42 & 116 & 72,05 & Josi & 9 & 29 & 34 & 14 & 37,66 \\
\hline
\end{tabular}

Nota: * Percentual de Segregação: Número de registros em grupo de mesmo sexo / total de registros do participante. 
Silva, Pontes, Silva, Magalhães \& Bichara (2006). Diferenças de Gêneros nos Grupos de Brincadeira na Rua: A Hipótese de Aproximação Unilateral.

\begin{tabular}{|c|c|c|}
\hline Brincadeira & $I P S$ & Classificação \\
\hline Porrinha & 1 & $\mathrm{TM}$ \\
\hline Futebol de botão & 0,95 & $\mathrm{PM}$ \\
\hline Baladeira & 0,94 & PM \\
\hline Pipa & 0,94 & PM \\
\hline Futebol & 0,93 & PM \\
\hline Ping-pong & 0,93 & $\mathrm{PM}$ \\
\hline Bode & 0,90 & PM \\
\hline Bozó & 0,89 & $\mathrm{PM}$ \\
\hline Adedonha & 0,83 & PM \\
\hline Mortal & 0,80 & $\mathrm{PM}$ \\
\hline Peteca & 0,80 & PM \\
\hline Cano & 0,78 & $\mathrm{PM}$ \\
\hline Carrasco & 0,76 & PM \\
\hline Bate parede & 0,68 & $\mathrm{PM}$ \\
\hline Polícia e Ladrão & 0,68 & $\mathrm{PM}$ \\
\hline Bandeirinha & 0,66 & $\mathrm{PM}$ \\
\hline Luta (espada, esgrima, karatê) & 0,59 & PM \\
\hline Tacobol & 0.58 & $\mathrm{PM}$ \\
\hline Fura-fura & 0,50 & PM \\
\hline Baralho & 0,40 & $\mathrm{M}$ \\
\hline Pira & 0,40 & M \\
\hline Macaca & 0,22 & M \\
\hline Estrela passela & 0,12 & M \\
\hline Pular corda & 0,08 & M \\
\hline Roda & $-0,07$ & M \\
\hline Boca-de-forno & $-0,26$ & M \\
\hline Cemitério & $-0,36$ & $\mathrm{M}$ \\
\hline Boneco (a) & $-0,50$ & $\mathrm{PF}$ \\
\hline Casinha / comidinha & $-0,62$ & $\mathrm{PF}$ \\
\hline Elástico & $-0,70$ & $\mathrm{PF}$ \\
\hline Estátua & $-1,00$ & $\mathrm{TF}$ \\
\hline
\end{tabular}

Arbitrariamente estabeleceram-se os seguintes critérios como limites de classificação: Brincadeiras Tipicamente Femininas $(\mathrm{TF})$ com IPS igual a -1 ; Brincadeiras Predominantemente Femininas (PF) com IPS entre - 0,99 e - 0,5 ; Brincadeiras Mistas (M) com IPS entre - 0,49 e + 0,49; Brincadeiras Predominantemente Masculinas (PM) com IPS entre + 0,5 e - 0,99 e Brincadeiras Tipicamente Masculinas (TM) com IPS igual a +1 .

A partir desses critérios, foram calculados os IPS e, com base nestes, classificadas as brincadeiras de maior freqüência e aquelas incluídas na categorização de brincadeiras tradicionais infantis (Kishimoto, 1993, 2000), conforme mostrado na Tabela 2.

Apenas duas brincadeiras apresentam perfil tipicamente homogêneo de gênero (estátua - TF; porrinha - TM), o que significa dizer que, embora em proporções diferentes, meninos e meninas brincam das mesmas brincadeiras, sugerindo que, a princípio, a estrutura ou estilo da brincadeira não são fatores de segregação sexual.
A maioria das brincadeiras (67,74\%) foi classificada como predominantemente masculina $(\mathrm{PM})$, havendo inclusive um grupo de brincadeiras com al to grau de tipificação masculina (IPS acima de 0,75\%). As brincadeiras de tipificação predominantemente masculina são, em geral, aquelas que envolvem alto grau de atividade e/ou confronto e desafio entre os participantes, podem ser também brincadeiras com características competitivas (perdedor e ganhador), tais como: baladeira, bozó, mortal, peteca, pipa, polícia e ladrão, futebol.

A tipificação predominantemente masculina pressupõe, entretanto, presença de meninas nas brincadeiras e este fato, ao lado da menor tipificação feminina nos grupos de brincadeiras, é consistente com a menor tendência das meninas à segregação e consequentemente, maior penetração no "mundo masculino". A classificação da pira e baralho como mistas e a menor tipificação em brincadeiras como tacobol, luta, fura-fura e bandeirinha (ainda que situadas no pólo masculino) também reforçam esta afirmação. O IPS da brincadeira de luta (0,59 - muito próximo ao perfil misto) parece um bom indicador da participação de meninas em brincadeiras tidas historicamente como essencialmente masculinas.

A participação das meninas em brincadeiras predominantemente masculinas parece conviver bem com a preferência por brincadeiras mais tranqüilas e mais ligadas à fantasia, como as rodas e as bonecas. Esses dados parecem indicar que as meninas estão sendo bem-sucedidas na tarefa de ampliar espaços, isto é, mantêm aquelas características e preferências historicamente consideradas "femininas" ao mesmo tempo em que se aproximam dos meninos. Os meninos, por sua vez, também apresentam uma penetração nas brincadeiras mais "femininas" (Ex.: casinha e roda), mas isso se dá em menor quantidade.

\section{Situando Individualmente as Preferências de Gênero}

Uma outra análise realizada foi a localização de alguns sujeitos-alvo (indivíduos com maior freqüência de registros na rua em cada grupo de sexo) na preferência por brincadeiras, partindo do pressuposto de que, se o IPS representa uma tendência de configuração típica do grupogênero de uma brincadeira, é possível identificar um padrão de preferência individual por brincadeiras tipificadas.

Para tipificar as preferências dos sujeitos foram computadas as médias de IPS das brincadeiras de cada um desses sujeitos-alvo. Esse cálculo resultou no chamado Índice de Preferência Individual (IPI), a partir do qual foi possível classificar as preferências individuais. Essa classificação se deu com base nos mesmos critérios de classificação dos IPS das brincadeiras. Essa análise possibilita a identificação de um perfil individual de preferências, respondendo a questões como: é possível identificar a proximidade de cada indivíduo com um grupogênero de brincadeiras? As preferências individuais de participação em grupos de brincadeiras sexualmente tipificadas repetem os padrões de tipificação encontrados para o grupo de brincadeiras? Esses padrões individuais 
Psicologia: Reflexão \& Crítica, 19(1), 114-121.

Tabela 3

\begin{tabular}{lll|lll}
\multicolumn{7}{l}{ Indice de Preferência Individual } \\
\hline \multicolumn{7}{c}{ Meninas } & \multicolumn{2}{c}{ Meninos } \\
\hline Partic. & IPI & Preferência & Partic. & IPI & Preferência \\
\hline Assu & 0,40 & M & Diel & 0,66 & PM \\
Lili & 0,45 & M & Elit & 0,72 & PM \\
Jani & 0,22 & M & Alex & 0,62 & PM \\
Hele & 0,02 & M & Thia & 0,76 & PM \\
Mari & 0,12 & M & Jode & 0,67 & PM \\
Elza & 0,22 & M & Carl & 0,75 & PM \\
Jessi & $-0,12$ & PF & Will & 0,77 & PM \\
Tais & 0,15 & M & Frank & 0,67 & PM \\
Hecr & 0,03 & M & Renan & 0,75 & PM \\
Josi & 0,15 & M & Valte & 0,53 & PM \\
& & & & &
\end{tabular}

são congruentes com as tendências encontradas para cada grupo de sexo? Os índices são mostrados na Tabela 3.

Os resultados encontrados indicam preferências intermediárias por todos os sujeitos em termos de grupogênero de brincadeiras, quer dizer, embora seja possível identificar brincadeiras com perfil homogêneo de sexo (aquelas brincadas por apenas um grupo de sexo), esse padrão parece não se repetir com as preferências individuais, em que nenhum dos sujeitos é classificado com preferência tipicamente masculina ou feminina. Os resultados mostraram ainda que todos os meninos têm preferências predominantemente masculinas (PM), confirmando sua pouca inserção nas brincadeiras femininas. O IPI mais próximo ao pólo feminino está representado pelo Valte (o,53). O índice, na verdade, não significa necessariamente que este garoto participa apenas das brincadeiras predominantemente femininas, podendo significar também a possibilidade de grande participação nas brincadeiras mistas (M), como fura-fura, pira etc. Pode-se dizer que Will é o sujeito mais afastado das brincadeiras femininas, classificado com o IPI mais alto (0,77).

No caso das meninas, todas apresentaram IPI bem abaixo dos meninos e a maioria das suas preferências foram classificadas como mistas (M), confirmando o maior trânsito entre os diferentes grupos-gêneros de brincadeira. Há um índice predominantemente feminino $(\mathrm{PF})$, ainda assim situado muito próximo ao pólo masculino (Jessi=- 0,12).

\section{Conclusões}

A freqüência e variedade de atividades e brincadeiras de crianças na rua parece credenciar este espaço como um importante contexto de desenvolvimento, uma expressão do tempo despendido e das possibilidades de amplas e variadas relações, interações, confrontos e aprendizagens.

Se os grupos de brincadeiras na rua se configuram como um espaço de partilha de uma grande quantidade e variedade de experiências, isso implica reconhecê-los como espaços de mediação na construção e abstração de regras, valores e padrões de comportamentos de grupo, inclusive as noções de diferenciação sexual. Os resultados apontam para diferenças nas formas de ocupação deste espaço e, com isso, nas relações que aí se estabelecem. A categoria gênero / sexo responde por grande parte dessas diferenças, o que nos permite afirmar que a rua é um espaço de ocupação sexualmente diferenciado. Foram encontradas tanto diferenças na participação na rua quanto na diversidade das culturas lúdicas.

Houve diferenças em termos de presença absoluta; em termos de número de registros e em termos de registros por grupos homogêneos de sexo. Esses dados indicam o predomínio dos meninos na ocupação da rua e sua permanência em idade mais avançada, sugerindo uma relação com os padrões de socialização e pressões diferenciadas sobre os dois grupos de gênero.

Os resultados relativos a diferenças de participação por sexo vão ao encontro de estudos anteriores, percebendo o fenômeno da ocupação da rua e das atividades que nela se desenvolvem como masculinamente dominado, resultando numa menor variedade da subcultura lúdica feminina na rua (Archer 1992; Beal 1994; Maccoby 1990).

Os meninos revelaram maior tendência à segregação. Entre as meninas, ao contrário, foi encontrada maior aproximação com o outro grupo de sexo em todas as faixas de idade estudadas, resultado demonstrado pela análise da composição dos grupos, pelo percentual de segregação dos dois grupos, pela tipificação das brincadeiras e ainda pelos índices de preferência individual. Foi percebida também uma nítida tendência à tipificação sexual das brincadeiras, sendo que na área estudada a maior tendência é para a tipificação das brincadeiras como predominantemente masculinas, com $67,74 \%$ das brincadeiras.

\section{Padrões de Diferenciação Sexual: a Hipótese da Aproximação Unilateral}

Além e por trás da maior quantidade e diversidade da cultura lúdica masculina na rua, a pouca homogeneização das brincadeiras (apenas uma com perfil tipicamente homogêneo de cada grupo de sexo) é significativa da penetração das meninas nesse "universo" predominantemente masculino, o que torna esse grupo importante referência de socialização para as elas. Esse trânsito fácil no grupo dos meninos pode ser um elemento significativo para a quebra da tendência à tipificação das brincadeiras, revelado pelo grande número de brincadeiras com IPS acima de 0,75\%, e apenas uma com IPS 1. Por outro lado, o reduzido número de brincadeiras predominantemente femininas, a baixa participação nestas e o IPS mais baixo podem ser analisados como indicativos da menor penetração dos meninos nas brincadeiras femininas. A inserção das meninas no universo de brincadeiras dos meninos pode significar a possibilidade ampliada de interação e de aprendizagem (habilidades, valores). Nossa suposição é de que a penetração das meninas no espaço masculino não se dá apenas pela pouca disponibilidade de parceiros (elas, mesmo em menor número, poderiam isolar-se em grupos segregados), mas seria, ao contrário, indicativo da resistência e pressão das meninas 
Silva, Pontes, Silva, Magalhães \& Bichara (2006). Diferenças de Gêneros nos Grupos de Brincadeira na Rua: A Hipótese de Aproximação Unilateral.

que, a despeito da escassez de parceiros de mesmo sexo e das pressões relacionadas à ideologia de papéis sexuais, invadem e se apropriam da cultura masculina, diminuindo, dessa forma, a distância entre os dois grupos de sexo.

Nossos dados parecem apoiar a hipótese de um terceiro padrão de tipificação de comportamento dos dois grupos (Martin \& Fabes 2001), que não seria de polarização, mas de “aproximação unilateral”, por meio do qual o comportamento de um dos sexos (nesse caso, o das meninas) muda mais rapidamente que o do outro, só que não em direção oposta, mas aproximando-se do outro grupo de sexo. Se as interações e atividades com o mesmo sexo têm nos meninos o efeito de reforçar comportamentos masculinos e por oposição, inibem ou desencorajam alguns comportamentos "femininos" (Ex.: como brincar de casinha ou ciranda), o mesmo efeito pode se dar no caso das meninas, o reforço ou a aprendizagem de comportamentos mais masculinos em função da convivência com eles. Nesse caso, a segregação parece ser menos intensa em função de que as meninas estão "invadindo" mais o espaço dos meninos. As meninas se aproximam do comportamento dos meninos, ainda que estes permaneçam mais rígidos em seus padrões.

Os dados da composição dos grupos de brincadeira por gênero, da segregação, da tipificação e da preferência por brincadeiras parecem apoiar essa suposição. A partir da for te presença das meninas nos grupos dos meninos, seria possível pensar em algumas conseqüências sobre o comportamento delas: a) poderia contribuir para o aumento da estereotipização feminina (internalização de papéis) pelo efeito tanto do contraste com os comportamentos masculinos, como pela própria pressão que os meninos exercem para a diferenciação de posturas e comportamentos, quer dizer, brincando juntos, os meninos pressionam as meninas a terem comportamentos adequados «às meninas» e a diferenciarem-se deles; b) ou, o que é a nossa suposição aqui, pode contribuir para a diminuição da estereotipização de papéis, tanto porque as meninas precisam tentar igualarse aos meninos para conquistarem / usufruírem de poder e status dentro dos grupos mistos (estratégias para serem aceitas no grupo) quanto porque brincando com meninos elas adquirem mais experiências deste grupo de sexo, mais oportunidade de vivenciar comportamentos e regras do sexo masculino, estão mais expostas à cultura dos meninos, aprendendo não apenas comportamentos dos meninos, mas também a conhecê-los melhor e essa experiência contribuiria para uma menor diferenciação. Esses são os argumentos para a hipótese de aproximação unilateral entre os grupos de gênero. As divergências encontradas neste estudo podem estar relacionadas às diferenças culturais, do contexto de grupos de rua ou ainda às idades dos participantes (1 a 18 anos), aspectos que fundamentam a necessidade de aprofundamento posterior da questão da aproximação unilateral.

\section{Referências}

Afonso, L. (1995). Gênero e processo de socialização em creches comunitárias. Cadernos de Pesquisa, 93, 12-21

Alexander, G. \& Hines, M. (1994) Gender labels and play styles: Their relative contribution to children's selection of playmates, Child Development. 65, 869-879.

Altmann, J. (1974). Observation study of behavior: Sampling methods. Behavior, 49(3-4), 227-267.

Archer, J. (1992) Childhood gender roles: Social context and organization. In M. Mc Gurk (Ed.), Childhood social development. Contemporary perspectives (pp.31-61). Hillsdale. USA. Lawrence Erlbaum

Beal, C.R. (1994) Boys and girls: The development of gender roles. USA: Mc Graw Hill.

Beraldo, K.E. (1993). O gênero de brincadeiras de crianças de 5 a 10 anos. Dissertação de Mestrado não publicada, Instituto de Psicologia, Universidade de São Paulo. São Paulo, SP.

Camaione, L. (1980). Interazione tra bambini. Roma. Armando Armando.

Carvalho, A.M.A. (1989). Brincar juntos: natureza e função da interação entre crianças. In C. Ades (Ed.), Etologia de animais e de homens (pp.199-2 10). São Paulo: Edicon/EDUSP.

Carvalho, A.M.A. (1992). Seletividade e vínculo na interação criançacriança. Tese de livre docência, Instituto de Psicologia, Univer sidade de São Paulo. São Paulo, SP.

Carvalho, A.M.A. \& Pedrosa, M.I. (2002). Cultura no grupo de brinquedo. Estudos de Psicologia (Natal), 7(1), 181-188.

Eibl-Eibesfeldt, I. (1989). Human Ethology. New York: Aldine de Gruyter.

Harris, J. (1999). Diga-me com quem anda... Rio de Janeiro: Objetiva. Johnson, J., Christie, J. \& Yawkey, T. (1999). Play and early childhood development ( $2^{\text {nd }}$. ed.). New York: Longmam.

Kishimoto, T.M. (1993). Jogos tradicionais infantis: ojogo, a criança e a educação. Petrópolis, RJ: Vozes.

Kishimoto, T.M. (2000). Jogo, brincadeira e a educação. São Paulo: Cortez.

Lordelo, E. (1995). Ambiente de desenvolvimento humano: uma análise a partir do contexto creche. Tese de Doutorado não-publicada, Instituto de Psicologia, Universidade de São Paulo. São Paulo, SP.

Maccoby, E. (1988). Gender as a social category. Developmental Psychology, 24, 755-765.

Maccoby, E. (1990). Gender and relationships: A developmental account. American Psychologist, 45, 513-520.

Maccoby, E. (1991). Gender and relationships: a reprise. American Psychologist, 46, 538-539.

Martin, C \& Fabes, R. (2001). The stability and consequences of young children's same-sex peer interactions. Developmental Psychology, 37(3), 43 1-446

Pedrosa, M.I. \& Carvalho, A.M.A. (1995). A Interação social e a construção da brincadeira. Cadernos de Pesquisa, 93, 60-65.

Pontes, F.A.R. (2000). Organização social na rua e a transmissão da cultura da brincadeira. Manuscrito não-publicado, Universidade Federal do Pará.

Segall, M., Dasen, P., Berry, J \& Poortinga, Y. (1990). Human behavior in global perspective: An introdution to croos-cultural psychology. New York: Pergamon Press.

Weinraub, M., Clemens, L. Sockloff, A., Ethridge, E., Gracely, E. \& Myers, B. (1984). The development of sex role stereotypes in the third year: relationships to gender labeling, gender identity, sex typed toy preference and family characteristics. Child Development, 55, 1493-1503. 